\title{
Formation of Hierarchical CuO Nanostructures on Copper Foil by Chemical Bath Deposition for Applications in Superhydrophobic Surfaces
}

\author{
Jenichi Clairvaux Felizco ${ }^{a}$ and Eduardo Magdaluyo Jr. ${ }^{b}$ \\ Department of Mining, Metallurgical and Materials Engineering, University of the Philippines, Quezon City Philippines
}

\begin{abstract}
Hierarchical $\mathrm{CuO}$ nanostructures (urchin-like and grassy island structure) were successfully synthesized by a simple chemical bath deposition method at low temperature of $70^{\circ} \mathrm{C}$ in a short reaction time of $1 \mathrm{~h}$. XRD analysis revealed the presence of pure crystalline monoclinic $\mathrm{CuO}$. Morphological analysis revealed the formation of spherical structures composed of numerous hair-like structures. The $\mathrm{pH}$ of the solution was also investigated to have a great effect on the morphology of the $\mathrm{CuO}$ nanostructures. At lower $\mathrm{pH}$, the structures tend to form urchin-like structures; while at higher $\mathrm{pH}$, the structures tend to form grass-like islands. A growth mechanism was also proposed in this paper. Lastly, wettability test proved the stable superhydrophobic property of the $\mathrm{CuO}$ nanostructured thin film surface.
\end{abstract}

\section{Introduction}

Cupric oxide $(\mathrm{CuO})$ is a p-type transitional metal oxide semiconductor with a narrow bandgap of 1.2-2.1 eV. It is naturally black in color, and observes a monoclinic crystal structure. Nanostructured $\mathrm{CuO}$, which is defined as having at least one dimension in the nanometer scale, differs in properties as with the bulk material due to quantum-size effects [1-2]. In any case, $\mathrm{CuO}$ nanostructures remain to exhibit superior optical, electrical, magnetic, thermal and electrochemical properties which render them usable for a wide variety of potential applications. These include solar cells [3], gas and chemical sensors [4-7], nanofluidics [8], photocatalysis [9-10], superhydrophobic surfaces [11], antimicrobial and antifungal agents [12-13] and electrochemical energy storage applications [14-19]. In particular, $\mathrm{CuO}$ superhydrophobic surfaces have been gaining interest because they have superior hydrophobicity but are very economical.

Several synthesis techniques for $\mathrm{CuO}$ nanostructures have been developed, such as thermal oxidation, wet chemical method, solution-phase synthesis, microwaveassisted synthesis, and chemical bath deposition. Among these, chemical bath deposition is least explored, but is one of the most promising methods because it is simple, inexpensive and potentially scalable. Also, chemical bath deposition on $\mathrm{Cu}$ foil allows direct formation onto a conductive substrate, which is ideal for use in energy storage devices such as lithium ion batteries and supercapacitors [14-19].

In this study, hierarchical $\mathrm{CuO}$ nanostructures were successfully synthesized by chemical bath deposition at a low temperature of $70^{\circ} \mathrm{C}$ in a short reaction time of $1 \mathrm{~h}$. The effect of $\mathrm{pH}$ on the morphology of the nanostructures was also investigated. A plausible growth mechanism is also proposed. Lastly, the superior hydrophobic properties of the unique $\mathrm{CuO}$ nanostructures were observed.

\section{Experimental}

High purity $\mathrm{Cu}$ foils $(99.99 \%, 1 \times 1 \mathrm{~cm})$ were manually ground using silicon carbide sheets and sonicated in $4 \mathrm{M}$ $\mathrm{HCl}$ solution for 15 mins to remove surface impurities and native oxide layers. In three beakers, $60 \mathrm{ml}$ of $0.1 \mathrm{M}$ $\mathrm{Cu}\left(\mathrm{NO}_{3}\right)_{2}$ solution was mixed with $20 \mathrm{ml} \mathrm{NH}_{3}$ solution of varying concentrations to achieve increasing $\mathrm{pH}$ values $(\mathrm{pH} \mathrm{10.2,11.3} \mathrm{and} \mathrm{11.9).} \mathrm{The} \mathrm{clean} \mathrm{Cu}$ foils were then submerged in the solutions after thorough mixing. The chemical bath was then heated to $70^{\circ} \mathrm{C}$ for $1 \mathrm{~h}$. The foils turned pitch black after the given reaction time. Finally, the foils were dried in an oven at $60^{\circ} \mathrm{C}$ for $3 \mathrm{~h}$.

\subsection{Characterization techniques}

The surface morphology of the $\mathrm{CuO}$ nanostructures was examined using scanning electron microscope (JEOL 5300 ) operating at $25 \mathrm{kV}$. The composition and crystal structure of the as-grown $\mathrm{CuO}$ nanostructures were determined by Shimadzu X-ray diffractometer (XRD7000) operated at $40 \mathrm{kV}$ and $30 \mathrm{~mA}$ with $\mathrm{Cu} \mathrm{Ka}$ radiation in the range of $30-80^{\circ}$. Wettability tests against water were performed using a simple contact angle set up.

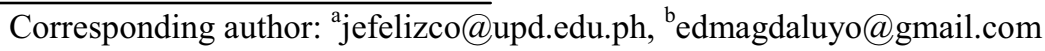




\section{Results and discussion}

\subsection{Structural analysis}

Figure 1 shows the XRD pattern of the $\mathrm{CuO}$ nanostructures formed. Highest peaks located at $43.4^{\circ}$, $50.1^{\circ}$ and $73.9^{\circ}$ represent pure metallic $\mathrm{Cu}$, which is the substrate used. The other characteristics peaks located at $32.5^{\circ}, 36.3^{\circ}$ and $39.4^{\circ} \mathrm{can}$ be attributed to (110), (11-1) and (111) peaks of pure monoclinic $\mathrm{CuO}$ (JCPDS 05661). This signifies that no contaminations were detected in the sample.

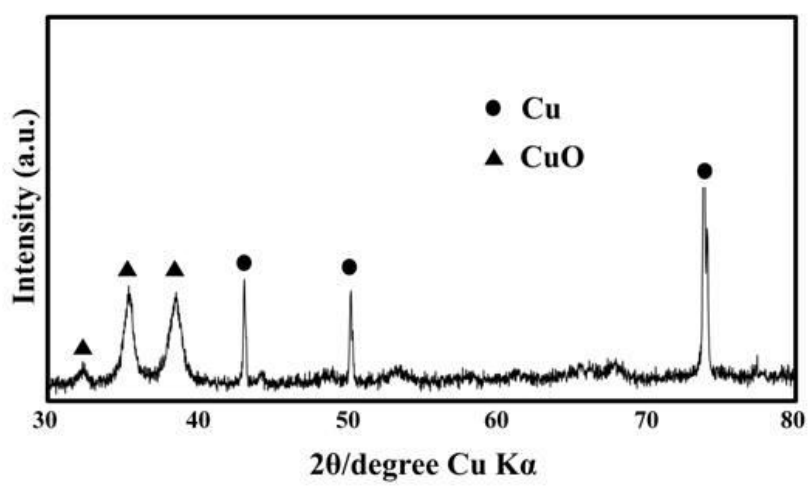

Figure 1. XRD pattern of urchin-like $\mathrm{CuO}$ nanostructure.

\subsection{Morphological analysis}

Figure 2 shows the SEM images of the hierarchical $\mathrm{CuO}$ nanostructures formed at $\mathrm{pH} \mathrm{10.2,11.3} \mathrm{and} \mathrm{11.9.} \mathrm{The}$ nanostructures were synthesized between $\mathrm{pH} 10$ to 12 because the high alkalinity favors the oxidation of the $\mathrm{Cu}$ foils. At $\mathrm{pH}$ 10.2, spherical structures comprised of numerous nanowires were produced, resembling an urchin structure. The diameters of these urchin-like nanostructures were $2-5 \mu \mathrm{m}$. When the $\mathrm{pH}$ was increased to 11.3 , similar urchin-like structures were formed, but are aggregated to form large clumps. At a very high $\mathrm{pH}$ of 11.9, nanowires are grouped together in the form of islands. This shows that $\mathrm{pH}$ greatly affects the morphology of the $\mathrm{CuO}$ nanostructures.

\subsection{Proposed Formation Mechanism}

Shown below are the reactions involved in the formation of $\mathrm{CuO}$ nanostructures:

$$
\mathrm{Cu}^{2+}+4 \mathrm{NH}_{3} \rightarrow\left[\mathrm{Cu}\left(\mathrm{NH}_{3}\right)_{4}\right]^{2+}
$$

$$
\begin{gathered}
{\left[\mathrm{Cu}\left(\mathrm{NH}_{3}\right)_{4}\right]^{2+}+2 \mathrm{OH}^{-} \rightarrow \mathrm{Cu}(\mathrm{OH})_{2}+\mathrm{NH}_{4} \mathrm{OH}} \\
\mathrm{Cu}(\mathrm{OH})_{2} \rightarrow \mathrm{CuO}+\mathrm{H}_{2} \mathrm{O}
\end{gathered}
$$

$\mathrm{Cu}^{2+}$ ions coming both from the substrate and from the chemical bath react with $\mathrm{NH}_{3}$ to form a copperammonium complex. $\mathrm{OH}^{-}$ions which come from the dissociation of ammonia to ammonium hydroxide then reacts with this complex to form $\mathrm{Cu}(\mathrm{OH})_{2}$. Then, upon dehydration caused by exposure to high temperature $\left(70^{\circ} \mathrm{C}\right)$, oxidation to $\mathrm{CuO}$ occurred.

Figure 3 shows a plausible growth mechanism of the hirerarchical $\mathrm{CuO}$ nanostructures. It starts with the formation of $\mathrm{Cu}(\mathrm{OH})_{2}$ nuclei. These nuclei then grow into nanowires, followed by oriented attachment. At lower $\mathrm{pH}$, preferentially oriented attachment is favored. This is because at low $\mathrm{pH}$, less $\mathrm{OH}^{-}$ions are present, which drives the oxidation to $\mathrm{CuO}$ at a slow pace. This means that the nanowires are given more time to preferentially attach in an orderly manner, which in this case is urchinlike formation. When $\mathrm{pH}$ is increased to 11.3 , a less orderly structure composed of aggregated urchin-like structures was formed. The possible reason for this is the presence of more $\mathrm{OH}^{-}$ions that drives the reaction faster, resulting to the disruption of the orderly formation of urchin-like structures because oxidation was achieved at a faster pace. The incomplete urchin-like structures have high surface energy, which led to aggregation to form clumps. Finally, at a very high $\mathrm{pH}$ of 11.9 , the nanowires tend to be much easily attracted to each other as dictated by the ultrafast-paced reaction. They then tend to be attracted in a parallel fashion into small groups (islands). These islands then tend to aggregate because of their high surface energy.

\subsection{Superhydrophobic properties}

Figure 4 shows the water contact angle measurements of the $\mathrm{CuO}$ nanostructures. The grassy island structures displayed the most superior hydrophobic property, having a contact angle of $152.1^{\circ}$. This is due to the very high surface area of the nanowires grouped into islands. The urchin-like nanostructures also showed good hydrophobic properties having a water contact angle of $125.4^{\circ}$. This is caused by the high surface area of the spherical structures, which is further improved by the presence of nanowires. The clumped urchin-like nanostructures showed the lowest hydrophobicity, with a water contact angle of $74.5^{\circ}$. The clumping caused the surface area of the urchin-like surface to greatly decrease. 


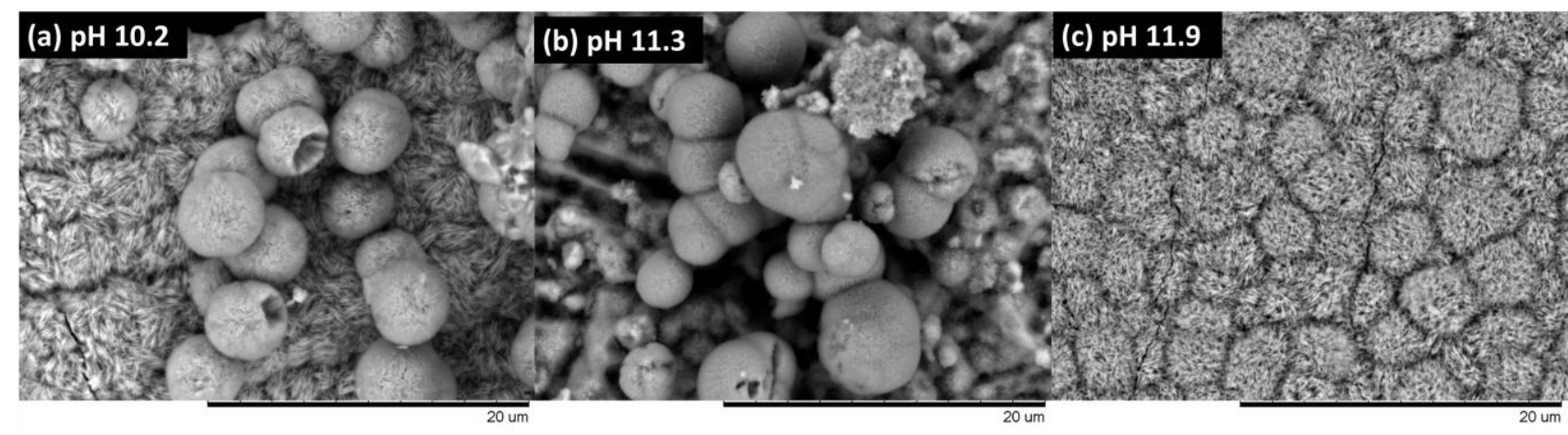

Figure 2. SEM images of hierarchical $\mathrm{CuO}$ nanostructures synthesized at different $\mathrm{pH}$ : (a) $\mathrm{pH} 10.2$, (b) $\mathrm{pH} 11.3$, and (c) $\mathrm{pH} 11.9$.

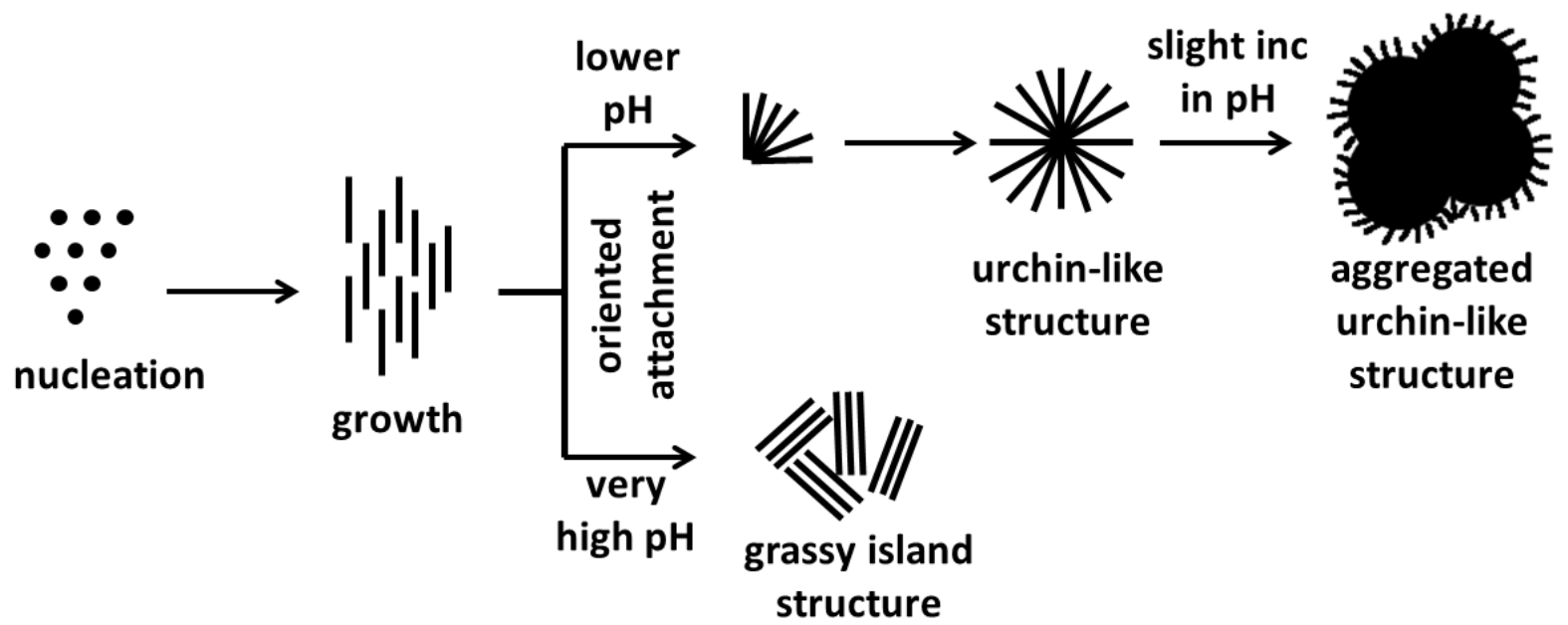

Figure 3. Schematic diagram of the proposed growth mechanism of hierarchical $\mathrm{CuO}$ nanostructures.

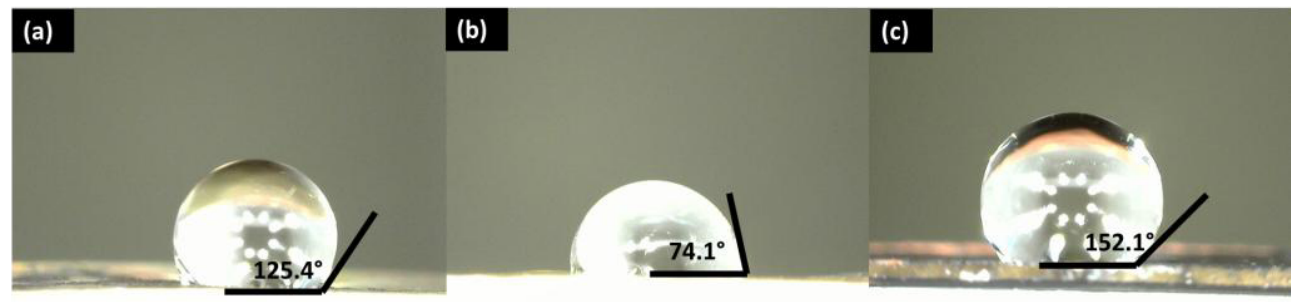

Figure 4. Schematic diagram of the proposed growth mechanism of hierarchical $\mathrm{CuO}$ nanostructures.

\section{Summary}

A simple chemical bath deposition method at low temperature $\left(70^{\circ} \mathrm{C}\right)$ in a short reaction time $(1 \mathrm{~h})$ to synthesize hierarchical $\mathrm{CuO}$ nanostructures was demonstrated in this study. XRD results confirmed the presence of pure crystalline monoclinic $\mathrm{CuO}$. SEM analysis showed the formation of urchin-like and grassy island structures. At a relatively low $\mathrm{pH}$ of 10.2, urchinlike structures were formed. When $\mathrm{pH}$ was increased to 11.3, these urchins aggregated. But at a very high $\mathrm{pH}$ value of 11.9, grassy island structures were formed. All of the structures showed superior superhydrophobic properties, which finds their role in producing potentially scalable, cheap but high quality superhydrophobic surfaces.

\section{References}

1. Q. Zhang, K. Zhang, D. Xu, G. Yang, H. Huang, F. Nie, et al., "CuO nanostructures: Synthesis, characterization, growth mechanisms, fundamental properties, and applications," Progress in Materials Science, vol. 60, pp. 208-337, 2014.

2. A. S. Zoolfakar, R. A. Rani, A. J. Morfa, A. P. O'Mullane, and K. Kalantar-zadeh, "Nanostructured copper oxide semiconductors: a perspective on materials, synthesis methods and applications," 
Journal of Materials Chemistry C, vol. 2, p. 5247, 2014.

3. V. Kumar, S. Masudy-Panah, C. C. Tan, T. K. S. Wong, D. Z. Chi, and G. K. Dalapati, "Copper oxide based low cost thin film solar cells," IEEE, pp. 443445, 2013.

4. C. Yang, X. Su, F. Xiao, J. Jian, and J. Wang, "Gas sensing properties of $\mathrm{CuO}$ nanorods synthesized by a microwave-assisted hydrothermal method," Sensors and Actuators B: Chemical, vol. 158, pp. 299-303, 2011.

5. C. Espro, N. Donato, S. Galvagno, D. Aloisio, S. Leonardi, and G. Neri, "CuO Nanowires-based Electrodes for Glucose Sensors," Chemical Engineering Transactions, vol. 41, pp. 415-420, 2014.

6. I. A. Khan, A. Badshah, M. A. Nadeem, N. Haider, and M. A. Nadeem, "A copper based metal-organic framework as single source for the synthesis of electrode materials for high-performance supercapacitors and glucose sensing applications," International Journal of Hydrogen Energy, vol. 39, pp. 19609-19620, 2014.

7. A. S. Zoolfakar, M. Z. Ahmad, R. A. Rani, J. Z. Ou, S. Balendhran, S. Zhuiykov, et al., "Nanostructured copper oxides as ethanol vapour sensors," Sensors and Actuators B: Chemical, vol. 185, pp. 620-627, 2013.

8. Y. Haldorai and J.-J. Shim, "Facile synthesis of $\mathrm{CuO}$ nanospindles from a 3D coordination complex and its application to nanofluids," Materials Letters, vol. 116, pp. 5-8, 2014.

9. X. Liu, Z. Li, Q. Zhang, F. Li, and T. Kong, "CuO nanowires prepared via a facile solution route and their photocatalytic property," Materials Letters, vol. 72, pp. 49-52, 2012.

10. L. Wang, Q. Zhou, G. Zhang, Y. Liang, B. Wang, W. Zhang, et al., "A facile room temperature solutionphase route to synthesize $\mathrm{CuO}$ nanowires with enhanced photocatalytic performance," Materials Letters, vol. 74, pp. 217-219, 2012.

11. J. Liu, X. Huang, Y. Li, Z. Li, Q. Chi, and G. Li, "Formation of hierarchical $\mathrm{CuO}$ microcabbages as stable bionic superhydrophobic materials via a room- temperature solution-immersion process," Solid State Sciences, vol. 10, pp. 1568-1576, 2008.

12. N. von Moos, L. Maillard, and V. I. Slaveykova, "Dynamics of sub-lethal effects of nano- $\mathrm{CuO}$ on the microalga Chlamydomonas reinhardtii during shortterm exposure," Aquat Toxicol, vol. 161, pp. 267-75, Apr 2015.

13. R. Chakraborty, R. K. Sarkar, A. K. Chatterjee, U. Manju, A. P. Chattopadhyay, and T. Basu, "A simple, fast and cost-effective method of synthesis of cupric oxide nanoparticle with promising antibacterial potency: Unraveling the biological and chemical modes of action," Biochim Biophys Acta, vol. 1850, pp. 845-56, Apr 2015.

14. A. Li, H. Song, W. Wan, J. Zhou, and X. Chen, "Copper oxide nanowire arrays synthesized by insitu thermal oxidation as an anode material for lithium-ion batteries," Electrochimica Acta, vol. 132, pp. 42-48, 2014.

15. M. Yang and Q. Gao, "Copper oxide and ordered mesoporous carbon composite with high performance using as anode material for lithium-ion battery," Microporous and Mesoporous Materials, vol. 143, pp. 230-235, 2011.

16. D. P. Dubal, G. S. Gund, R. Holze, and C. D. Lokhande, "Mild chemical strategy to grow microroses and micro-woolen like arranged $\mathrm{CuO}$ nanosheets for high performance supercapacitors," Journal of Power Sources, vol. 242, pp. 687-698, 2013.

17. Y. Fan, P.-F. Liu, and Z.-J. Yang, "CuO nanoparticles supported on carbon microspheres as electrode material for supercapacitors," Ionics, vol. 21, pp. 185-190, 2014.

18. J. Huang, H. Wu, D. Cao, and G. Wang, "Influence of $\mathrm{Ag}$ doped $\mathrm{CuO}$ nanosheet arrays on electrochemical behaviors for supercapacitors," Electrochimica Acta, vol. 75, pp. 208-212, 2012.

19. S. E. Moosavifard, J. Shamsi, S. Fani, and S. Kadkhodazade, "Facile synthesis of hierarchical $\mathrm{CuO}$ nanorod arrays on carbon nanofibers for highperformance supercapacitors," Ceramics International, vol. 40, pp. 15973-15979, 2014. 